\title{
A Lymphokine Regulates Expression of Alpha-1-Proteinase Inhibitor in Human Monocytes and Macrophages
}

\author{
Shuhei Takemura, Thomas H. Rossing, and David H. Perlmutter
}

Divisions of Gastroenterology, Nutrition, and Cell Biology, Children's Hospital; Pulmonary Division, Brigham and Women's Hospital; Departments of Pediatrics and Medicine, Harvard Medical School, Boston, Massachusetts 02115

\begin{abstract}
Biosynthesis and secretion of alpha-1-proteinase inhibitor $\left(\alpha_{1} P I\right)$ has been demonstrated in primary cultures of human mononuclear phagocytes, making it possible to study regulation of $\alpha_{1}$ PI in normal (PiMM) and homozygous-deficient (PiZZ) individuals. In this study, expression of $\alpha_{1}$ PI by blood monocytes, bronchoalveolar, and breast milk macrophages decreased during 1 wk in culture whereas expression of other secreted proteins increased. The addition of crude supernatants from mitogen-stimulated peripheral blood mononuclear cells to confluent monolayers of mononuclear phagocytes after $1 \mathrm{wk}$ in culture resulted in a 2- to 2.5-fold increase in $\alpha_{1}$ PI expression. The increase in $\alpha_{1}$ PI expression was dose- and time-dependent, and involved a mechanism acting at a pretranslational level as shown by an increase in specific messenger RNA content corresponding to the increase in synthesis and secretion of $\alpha_{1}$ PI. Although $\alpha_{1}$ PI was expressed in native form and in forms complexed with serine protease by monocytes early in culture, it was expressed in its native form alone when monocytes were incubated with the lymphokine after 1 wk in culture. The regulating factor had the characteristics of a polypeptide and was derived from $T$ lymphocytes, but it was not interferon-alpha, -beta, -gamma, or interleukin 2. This lymphokine also stimulated synthesis of $\alpha_{1} P I$ in monocytes of homozygous-deficient PiZZ individuals, but had minimal effect on secretion, thereby increasing the intracellular accumulation of the inhibitor and exaggerating the defect in secretion of $\alpha_{1}$ PI in these individuals. Regulation of mononuclear phagocyte $\alpha_{1}$ PI expression by a lymphokine provides a model for further analysis of the effect of enhanced synthesis on a defect in posttranslational processing/secretion and for analysis of differential regulation of protease and inhibitor expressed in the same cells.
\end{abstract}

\section{Introduction}

Alpha-1-proteinase inhibitor $\left(\alpha_{1} \mathrm{PI}\right)^{1}$ is thought to play an important role in elastic tissue injury and repair because it rapidly inactivates neutrophil elastase (reviewed in reference 1). It is a

Address correspondence to Dr. Perlmutter.

Received for publication 3 October 1985 and in revised form 19 November 1985 .

1. Abbreviations used in this paper: $\alpha_{1} \mathrm{PI}$, alpha-1-proteinase inhibitor; Con A, concanavalin A; DME, Dulbecco's modified Eagle's medium; IL-1 and IL-2, interleukins 1 and 2; PWM, pokeweed mitogen; SDSPAGE, sodium dodecyl sulfate-polyacrylamide gel electrophoresis; TPCK, $N$-tosyl-L-phenyl-alanine chloromethyl ketone.

J. Clin. Invest.

(C) The American Society for Clinical Investigation, Inc.

$0021-9738 / 86 / 04 / 1207 / 07 \quad \$ 1.00$

Volume 77, April 1986, 1207-1213 $52,000-55,000$-mol-wt single-chain glycoprotein encoded by a 10.2-kilobase $(\mathrm{kb})$ gene $(2)$ on human chromosome $14(3,4)$. Several polymorphic variants of this inhibitor (PiZZ and PiSZ) have been associated with moderate to severe reduction in plasma concentration of the inhibitor, chronic liver disease, and pulmonary emphysema.

Liver is the predominant site of synthesis $(5,6)$, but human monocytes and macrophages also synthesize and secrete $\alpha_{1} \mathrm{PI}$ (7). Furthermore, the cellular defect in homozygous PiZZ $\alpha_{1}$ PI deficiency, a selective decrease in rate of secretion of $\alpha_{1} \mathrm{PI}$, is expressed in human monocytes from PiZZ individuals (8). Thus, blood monocytes and tissue macrophages in primary cell culture make it possible to study the expression and regulation of $\alpha_{1} \mathrm{PI}$ in normal and deficient individuals.

Although plasma concentrations of $\alpha_{1} \mathrm{PI}$ are known to increase during acute inflammation, pregnancy, and oral contraceptive administration (9), relatively little information about the regulation of $\alpha_{1} \mathrm{PI}$ is available. In primary cultures of human blood monocytes, bronchoalveolar macrophages, and breast milk macrophages we previously observed a decrease in $\alpha_{1}$ PI messenger RNA (mRNA) content and a corresponding decrease in synthesis and secretion of $\alpha_{1}$ PI during the first $10 \mathrm{~d}$ in culture (7). This decrease in expression of $\alpha_{1}$ PI during maturation in culture was not caused by a change in cell viability or total metabolic activity, as total protein synthesis and synthesis of other specific secreted proteins increased during that interval. These observations suggested that $\alpha_{1}$ PI was regulated by a factor elaborated in vitro or by loss of an in vivo regulating factor. Expression of DR antigen by human monocytes also decreases during the first week in culture but the decrease can be prevented by the addition of a lymphocyte product, interferon-gamma, to the cell culture fluid (10). In the following study, another lymphokine was shown to increase the expression of $\alpha_{1} \mathrm{PI}$ in mononuclear phagocytes, and, as a result, to accentuate the defect in secretion of $\alpha_{1}$ PI in severely deficient individuals.

\section{Methods}

Materials. Dulbecco's modified Eagle's medium (DME), DME lacking methionine, and RPMI 1640 were purchased from Gibco, Grand Island, NY, and Hank's balanced salt solution (HBSS) and medium 199 from Microbiological Assoc., Bethesda, MD. Fetal bovine serum, L-glutamine, and penicillin-streptomycin were from Flow Laboratories, McLean, VA. ${ }^{35}$ S $]$ methionine (specific radioactivity, $\sim 1,000 \mathrm{Ci} / \mathrm{mmol}$ ) and [ $\left.{ }^{32} \mathrm{P}\right]$ deoxycytidine triphosphate (specific radioactivity, $\sim 3,000 \mathrm{Ci} / \mathrm{mmol}$ ) were obtained from New England Nuclear, Boston, MA, and $\left[{ }^{14} \mathrm{C}\right]$ methylated protein standards were obtained from Amersham Radiochemicals, Arlington Heights, IL. Other reagents included sodium deoxycholic acid, ethidium bromide, 2-mercaptoethanol, porcine pancreatic elastase, and Hepes from Sigma Chemical Co., St. Louis, MO; Triton X-100 from Mallinckrodt, Inc., St. Louis, MO; sodium dodecyl sulfate (SDS) and acrylamide from Bio-Rad Laboratories, Richmond, CA; IgG-Sorb from Enzyme Center, Cambridge, MA; leupeptin from Peptide Research Institute, Osaka, Japan; pepstatin A from Calbiochem- 
Behring Corp., San Diego, CA, concanavalin A (Con A) from Miles Laboratories, Naperville, IL; Ficoll from Pharmacia AB, Uppsala, Sweden; sodium diatrizoate (Hypaque sodium $50 \% \mathrm{wt} / \mathrm{vol}$ ) from Winthrop Laboratories; immobilized $N$-tosyl-L-phenyl-alanine chloromethyl ketone (TPCK) trypsin from Worthington Biochemicals, Freehold, NJ; pokeweed mitogen (PWM) from Burroughs Wellcome, Research Triangle Park, NC; cesium chloride from Bethesda Research Laboratories, Gaithersburg, MD; guanidine isothiocyanate from Fluka AG, Buchs, Switzerland; and sodium $N$-laurylsarcosinate from ICN Pharmaceuticals, Plainville, NY. Rabbit anti-human $\alpha_{1}$ PI was purchased from Dako Corp., Santa Barbara, CA; goat anti-human $\alpha_{1} \mathrm{PI}$, goat anti-human lysozyme, goat anti-human factor $B$, and goat anti-human $\mathrm{C} 3$ were obtained from Atlantic Antibodies, Scarborough, ME. Recombinant-generated human interferons were obtained from Roche Institute of Molecular Biology, Nutley, NJ (alpha), Cetus Corp., Emeryville, CA (beta), and Genentech, San Francisco, CA (gamma). The specific activity of interferon-gamma was $1.9 \times 10^{7} \mathrm{IU}$ antiviral activity/mg protein. Purified human monocyte interleukin 1 (IL-1) was a gift from C. A. Dinarello (Boston, MA). Supernatants from alloantigen-stimulated $\mathrm{T}^{+}$lymphocyte clones were gifts from Dr. R. Geha (Boston, MA).

Separation and culture of monocytes and macrophages. Confluent monolayers of human peripheral blood monocytes were established by adherence of dextran-purified leukocytes on siliconized glass as previously described (11). Bronchoalveolar macrophages were obtained from sterile saline bronchial lavage, and breast milk macrophages were from milk expressed during the first $4 \mathrm{~d}$ of lactation. After centrifugation and washing, cells were allowed to adhere to siliconized glass coverslips $(12,13)$.

Lymphokines. Peripheral blood mononuclear cells $\left(2 \times 10^{6} / \mathrm{ml}\right)$ were isolated by Ficoll-Hypaque density gradient centrifugation (14), depleted of monocytes by one adherence step, and then incubated for 2-6 d in RPMI 1640 containing $2 \%$ heat-inactivated fetal calf serum, $0.05 \mathrm{mM}$ 2-mercaptoethanol, $5 \mathrm{mM}$ Hepes, $100 \mathrm{U} / \mathrm{ml}$ penicillin, $100 \mu \mathrm{g} / \mathrm{ml} \mathrm{strep-}$ tomycin, $2 \mathrm{mM}$ L-glutamine with $2 \mu \mathrm{g} / \mathrm{ml} \mathrm{Con} \mathrm{A} \mathrm{or} 10 \mu \mathrm{g} / \mathrm{ml} \mathrm{PWM}$. After centrifugation, supernatants were separated from cells, filtered, and stored at $-70^{\circ} \mathrm{C}$. Some aliquots were dialyzed against DME lacking methionine so that they could be included in cell culture fluid during biosynthetic labeling. Control culture supernatants were prepared by culturing peripheral blood mononuclear cells in the same medium but supplementing with Con A or PWM only after supernatants were separated from cells. Supernatants were also obtained from Con A-stimulated T lymphocytes and from alloreactive $\mathrm{T} 4^{+}$lymphocyte clones (15). T lymphocytes were collected from peripheral blood specimens by Ficoll-Hypaque centrifugation, enrichment by rosetting with sheep erythrocytes, passage of E + cells through nylon wool columns, and cultivation of cells not adhering to siliconized glass surfaces. In specified experiments crude lymphokine preparations were incubated at $56^{\circ} \mathrm{C}$ and $70^{\circ} \mathrm{C}$ for $60 \mathrm{~min}$ or to $100^{\circ} \mathrm{C}$ for $5 \mathrm{~min}$, adsorbed by immobilized TPCK-treated trypsin in $0.05 \mathrm{M}$ Tris $\mathrm{HCl}(\mathrm{pH} 8.0) / 0.05 \mathrm{M} \mathrm{NaCl}$ for $60 \mathrm{~min}$ at $37^{\circ} \mathrm{C}$ or adsorbed by $5-500 \mathrm{ng}$ mouse monoclonal anti-human interferon-gamma. The effect of these lymphokine preparations on $\alpha_{1}$ PI expression by mononuclear phagocytes was then compared to that of the usual preparations.

Biosynthetic labeling. Confluent monolayers were rinsed and incubated at $37^{\circ} \mathrm{C}$ for $3 \mathrm{~h}$ in the presence of methionine-free medium containing $\left[{ }^{35} \mathrm{~S}\right]$ methionine $(500 \mu \mathrm{Ci} / \mathrm{ml})$. Methods for solubilization of cells and clarification of cell lysates after labeling have been described (7). Total protein synthesis was estimated by trichloroacetic acid (TCA) precipitation of aliquots of cell lysates and culture fluid (16).

Immunoprecipitation and SDS-polyacrylamide gel electrophoresis $(P A G E)$. For immunoprecipitation, aliquots of cell lysate or medium were incubated overnight at $4^{\circ} \mathrm{C}$ in $1 \%$ Triton $\mathrm{X}-100 / 1.0 \% \mathrm{SDS} / 0.5 \%$ deoxycholic acid, with excess antibody. Immune complexes were precipitated with excess formalin-fixed staphylococci-bearing protein A, washed, released by boiling in sample buffer, and applied to $9.0 \%$ SDSPAGE under reducing conditions as described by Laemmli $(17) .{ }^{14} \mathrm{C}$ methylated molecular size markers $(200,000,92,500,68,000,46,000$, and $30,000 \mathrm{~mol} \mathrm{wt}$ ) were included on all gels. After electrophoresis, gels were stained in Coomassie Brilliant Blue, destained, impregnated with 2,5-diphenyloxazole (EN ${ }^{3} \mathrm{HANCE}$, New England Nuclear), and dried for fluorography on XAR x-ray film (Eastman Kodak Co., Rochester, NY). Complexing of $\alpha_{1} \mathrm{PI}$ with proteases was examined by treatment of extracellular media with protease in $0.05 \mathrm{M}$ Tris $\mathrm{HCl}(\mathrm{pH} 8.0) / 0.05$ $\mathrm{NaCl}$ at $25^{\circ} \mathrm{C}$ for $10 \mathrm{~min}$. Reactions were terminated with 100 -fold excess phenylmethylsulfonyl fluoride. Proteases included bovine alpha-chymotrypsin and porcine pancreatic elastase.

Detection of RNA by RNA blot analysis. Total cellular RNA was isolated from adherent monolayers of monocytes and macrophages by guanidine isothiocyanate extraction and ethanol precipitation (18). RNA was quantitated by absorbance at $260 \mathrm{~nm}$ and solubilized for agaroseformaldehyde gel electrophoresis and transfer to nitrocellulose filters (19). Filters were then hybridized with ${ }^{32} \mathrm{P}$-labeled $\alpha_{1}$ PI-specific complementary (c) DNA (20), complement factor B-specific cDNA (21), and complement C3-specific cDNA (22). After hybridization, filters were washed extensively, dried, and exposed to $\mathrm{x}$-ray film for autoradiography.

\section{Results}

Effect of crude lymphokine on $\alpha_{1} P I$ expression by monocytes and macrophages. Peripheral blood monocytes were maintained in culture for $10 \mathrm{~d}$. At specified intervals, monolayers were incubated with supernatants of unstimulated and Con A-stimulated peripheral blood mononuclear cells and then biosynthetically labeled for $3 \mathrm{~h}$ (Fig. 1). As shown in previous experiments (7), synthesis and secretion of $\alpha_{1}$ PI decreased during these $10 \mathrm{~d}$ in culture, as total protein synthesis and synthesis of other specific proteins, such as lysozyme, complement proteins $\mathrm{C} 2$ and factor $B$, increased (data not shown). Incubation with the crude lymphokine, however, led to an increase in expression of $\alpha_{1}$ PI by days $4-6$, but even more noticeably by days 7-9 in culture. In-

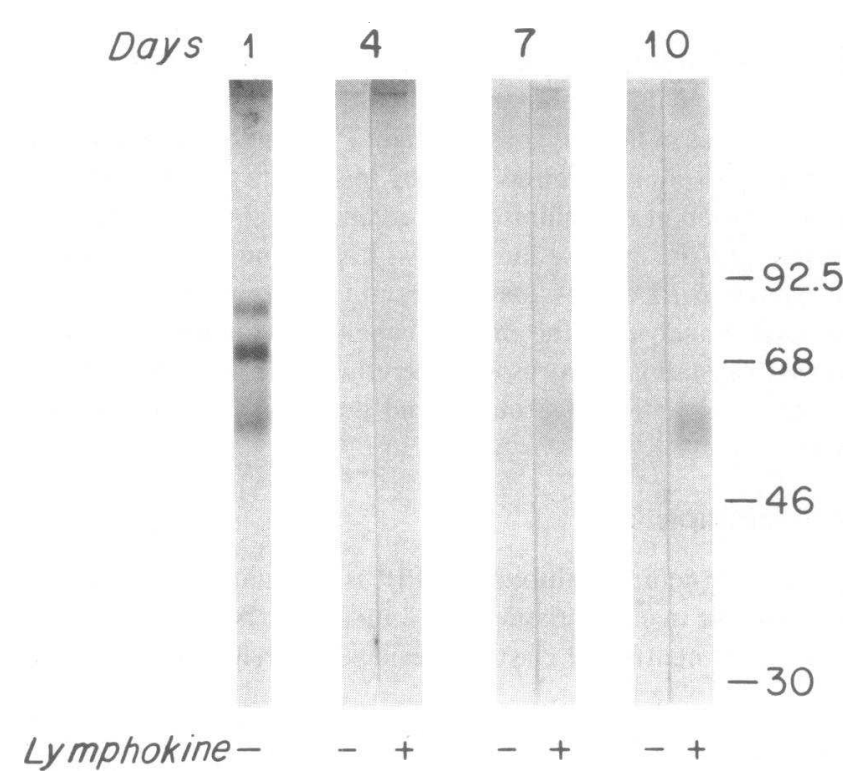

Figure 1. Effect of time in culture on and supernatants of Con A-stimulated peripheral blood mononuclear cells on biosynthesis and secretion of $\alpha_{1}$ PI by monocytes. Extracellular media from radiolabeled peripheral blood monocytes in culture for $1,4,7$, and $9 \mathrm{~d}$ were immunoprecipitated with anti-human $\alpha_{1}$ PI. Equivalent volumes of each sample were used for immunoprecipitation despite increases of 3-, 8-, and 10-fold in total TCA-precipitable protein during that time. Monocytes were incubated in control supernatant $(-)$ or supernatant of Con A-stimulated mononuclear cells $(+)$ at $1: 10$ dilution for $48 \mathrm{~h}$ before labeling. Total TCA-precipitable protein was not independently affected by incubation in these supernatants. Molecular mass markers are indicated. 
cubation with the crude lymphokine did not affect the expression of $\alpha_{1} \mathrm{PI}$ in freshly isolated monocytes or macrophages (data not shown). These results are consistent with those reported by Boldt et al. (23) for immunohistochemically detected cell-surface $\alpha_{1}$ PI on unfractionated peripheral blood mononuclear cells incubated with Con A. During the initial $24 \mathrm{~h}$ in culture, monocytes secrete $\alpha_{1} \mathrm{PI}$ in the native $(55,000 \mathrm{~mol} \mathrm{wt})$ form and in forms complexed with serine protease $(66,000$ and $75,000 \mathrm{~mol} \mathrm{wt})$. In contrast, after $7 \mathrm{~d}$ in culture, lymphokine-treated monocytes secreted $\alpha_{1}$ PI in the native $(55,000 \mathrm{~mol} \mathrm{wt})$ form alone. Native $\alpha_{1}$ PI secreted by such lymphokine-treated monocytes was not oxidatively inactivated, as demonstrated by the formation of a 75,000-mol wt radiolabeled band after addition of exogenous unlabeled elastase (data not shown).

Supernatants from Con A-stimulated mononuclear cells also increased expression of $\alpha_{1}$ PI by alveolar and breast milk macrophages (Fig. 2, left). The effect of the lymphokine on $\alpha_{1}$ PI expression was specific, in that total protein synthesis and synthesis of another specific protein, complement component C3 (Fig. 2, right), were not affected.

The effect of this lymphokine on expression of $\alpha_{1}$ PI in monocytes and alveolar macrophages involved a pretranslational mechanism as demonstrated by an increase in $\alpha_{1}$ PI mRNA con-
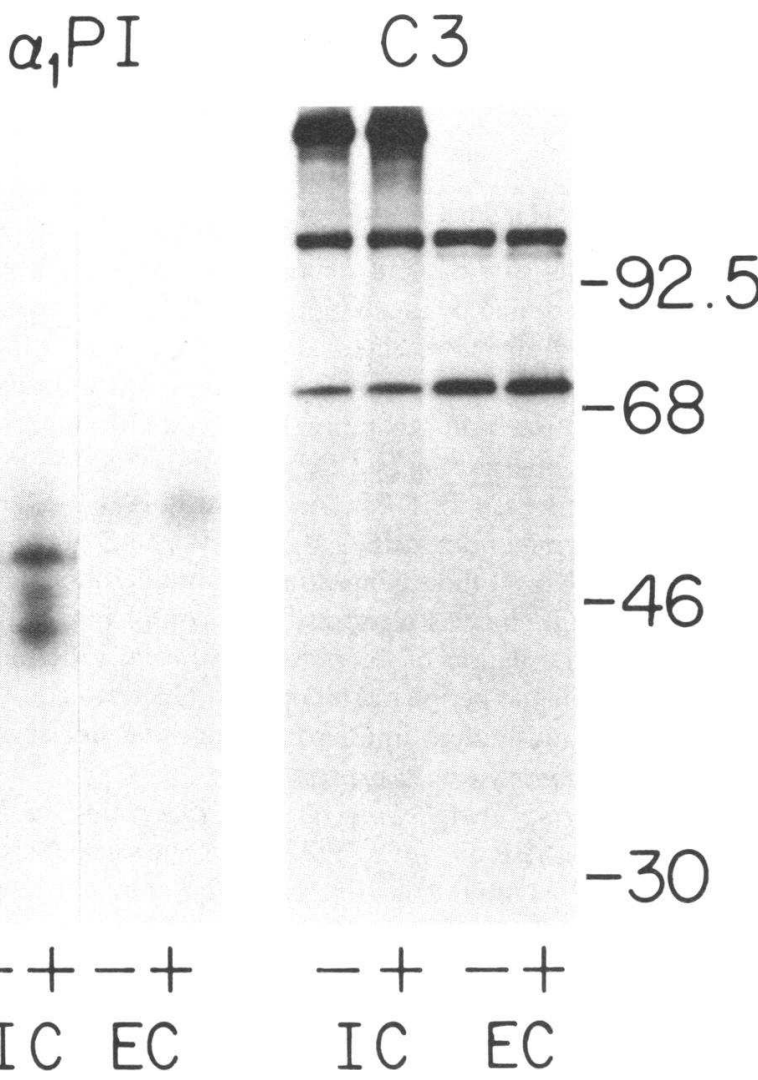

Figure 2. Effect of supernatants of Con A-stimulated peripheral blood mononuclear cells on biosynthesis and secretion of $\alpha_{1} \mathrm{PI}$ and $\mathrm{C} 3$ by alveolar macrophages. Intracellular lysates (IC) and extracellular media (EC) from radiolabeled alveolar macrophages after $9 \mathrm{~d}$ in culture were immunoprecipitated with anti-human $\alpha_{1}$ PI (left) and then anti-human C3 (right). Macrophages were incubated in control supernatant $(-)$ or supernatant of Con A-stimulated peripheral blood mononuclear cells $(+)$ at 1:10 dilution for $48 \mathrm{~h}$ before labeling. Total TCA-precipitable protein did not vary significantly between samples. Molecular mass markers are indicated.

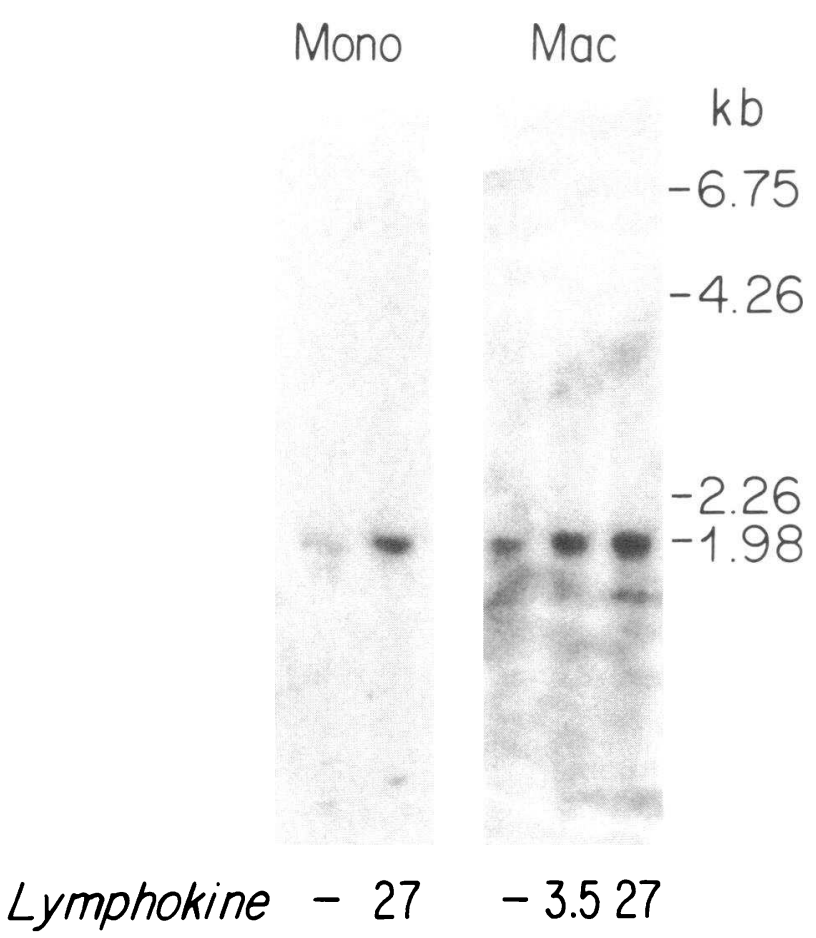

Figure 3. Detection of $\alpha_{1}$ PI mRNA in blood monocytes and alveolar macrophages after incubation with lymphokine. Equivalent amounts of total cellular RNA from blood monocytes (left) and alveolar macrophages (right) after $9 \mathrm{~d}$ in culture and incubation for $48 \mathrm{~h}$ in control $(-)$ or lymphokine supernatants at various relative concentrations were applied to RNA blot analysis. Separate blots were hybridized with radiolabeled cDNA for $\alpha_{1}$ PI. The number of cells from which RNA was isolated did not vary significantly after incubation with control or lymphokine supernatants. DNA size markers are indicated.

tent corresponding to the increase in synthesis and secretion of $\alpha_{1}$ PI (Fig. 3). There was also an increase in factor B mRNA content but no change in C3 mRNA content in lymphokinetreated macrophages (data not shown).

Characteristics of the lymphokine stimulating $\alpha_{1} P I$ expression. The effect of supernatant from Con A-stimulated mononuclear cells on $\alpha_{1}$ PI expression was dose- and time-dependent (Fig. 4). Expression of $\alpha_{1} \mathrm{PI}$ increased with increasing relative lymphokine concentration to 270 (dilution 1:10), decreasing slightly at higher relative concentrations (Fig. 4, left). At the optimal relative lymphokine concentration the increase in $\alpha_{1} \mathrm{PI}$ was $200-250 \%$ of control, as demonstrated by direct scintillation counting of radiolabeled bands excised from the gels of four separate experiments (Fig. 5). At this relative lymphokine concentration, expression of $\alpha_{1}$ PI was $\sim 55-60 \%$ of that present in the cell culture fluid of unstimulated monocytes during the first $24 \mathrm{~h}$ in culture. The effect of the lymphokine on synthesis and secretion of $\alpha_{1}$ PI reached its maximum between 24 and $48 \mathrm{~h}$ of incubation (Fig. 4, right). There was no further change between 48 and $72 \mathrm{~h}$ of incubation in lymphokine. The increase in $\alpha_{1} \mathrm{PI}$ expression was not produced by a direct action of Con $\mathrm{A}$ or a product of unstimulated peripheral blood mononuclear cells on monocytes (Fig. 6).

Supernatants were also collected from peripheral blood mononuclear cells stimulated with Con A or PWM for varying intervals from 2 to $6 \mathrm{~d}$. $\alpha_{1} \mathrm{PI}$ expression by monocytes increased after incubation in each of these supernatants but increased 

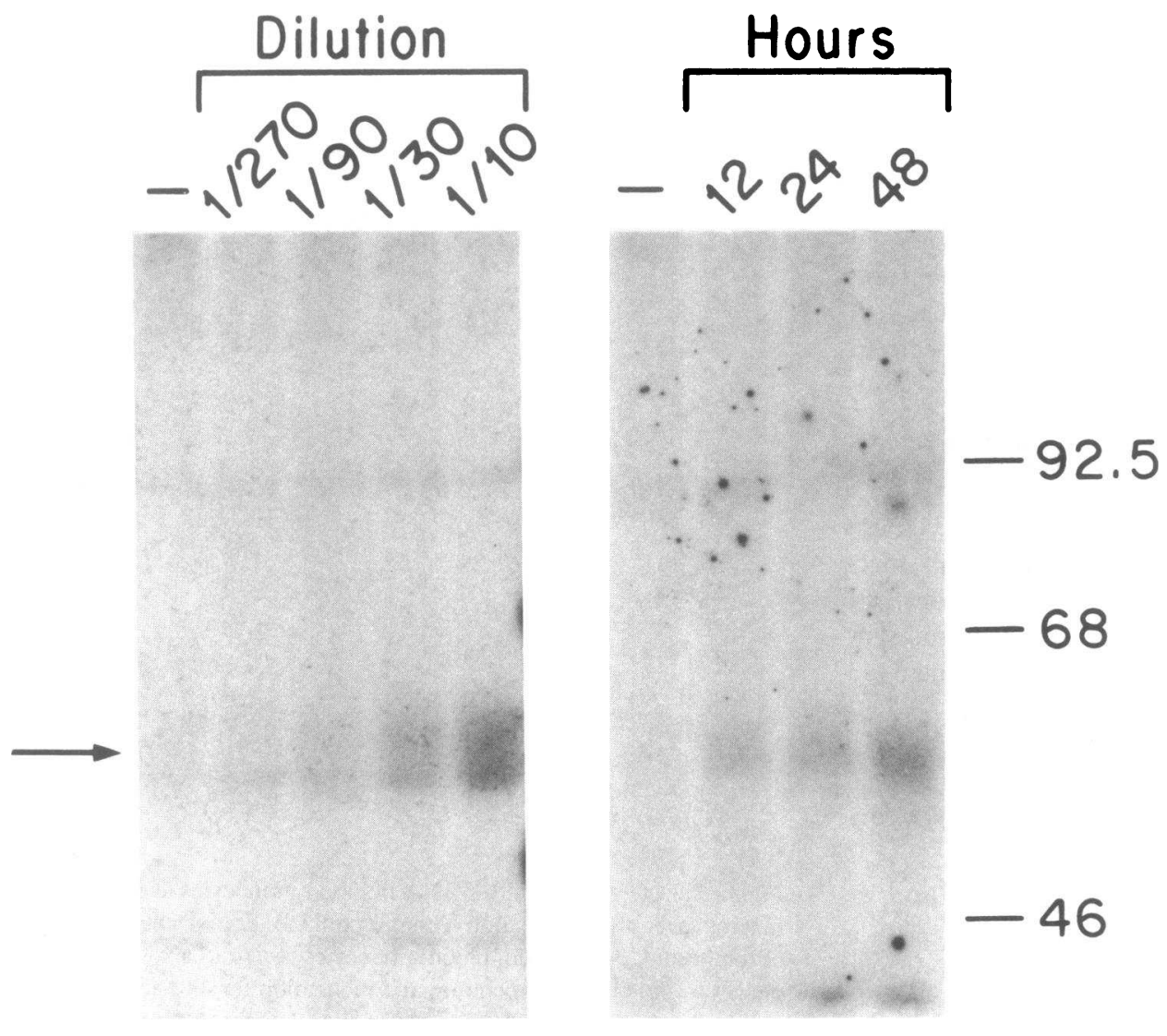

Figure 4. The effect of lymphokine supernatants on synthesis and secretion of $\alpha_{1}$ PI by monocytes is doseand time-dependent. Extracellular media from radiolabeled monocytes in culture for $9 \mathrm{~d}$ were immunoprecipitated with anti-human $\alpha_{1}$ PI. Monocytes were incubated with control $(-)$ or lymphokine supernatant at varying dilutions for $48 \mathrm{~h}$ (left) or lymphokine supernatants at $1: 10$ dilution for varying intervals (right) before labeling. Molecular mass markers are indicated. maximally in supernatants from peripheral blood mononuclear cells stimulated with Con A for $4 \mathrm{~d}$ (data not shown).

The effect of supernatants from Con A-stimulated peripheral blood $\mathrm{T}$ lymphocytes and supernatants from alloreactive $\mathrm{T} 4^{+}$ lymphocyte clones was similar to that of supernatants from Con A stimulated peripheral blood mononuclear cells (data not shown). The factor in supernatants of Con A-stimulated mono-

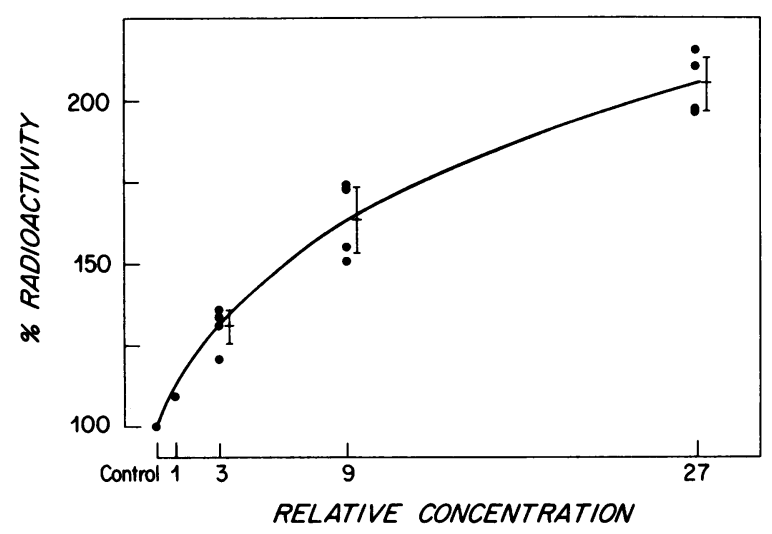

Figure 5. The effect of lymphokine supernatants on synthesis and secretion of $\alpha_{1} \mathrm{PI}$ by monocytes is dose-dependent. After $7 \mathrm{~d}$ in culture monocytes were incubated for $48 \mathrm{~h}$ with control or lymphokine supernatants, and then radiolabeled. Extracellular media were immunoprecipitated and precipitates subjected to SDS-PAGE and fluorography. The radiolabeled band for native, 55,000-mol-wt $\alpha_{1}$ PI was excised from the gel, solubilized, and relative radioactivity determined by liquid scintillation counting. Data shown are for four separate experiments. Radioactivity is expressed as percentage as compared with control \pm 1 SD. nuclear cells responsible for increasing monocyte $\alpha_{1} \mathrm{PI}$ expression had the characteristics of a polypeptide. The effect of the supernatants was abrogated by incubation at $70^{\circ} \mathrm{C}$ for $60 \mathrm{~min}$ and at $100^{\circ} \mathrm{C}$ for $5 \mathrm{~min}$ or by treatment of supernatants with trypsin (data not shown). Monocyte $\alpha_{1}$ PI expression was not affected by $24-h$ incubation with recombinant-generated human interferon-alpha $A$, interferon-alpha $D$, interferon-beta, interferongamma, or interleukin 2 (IL-2) at concentrations at 1-1,000 U/ $\mathrm{ml}$, or with purified human IL-1 at concentrations of $0.5-12.5$ $\mathrm{U} / \mathrm{ml}$ (not shown). At these concentrations, interferon-alpha and interferon-gamma increased expression of complement $\mathrm{C} 2$ and factor B (24). Depletion of interferon-gamma in supernatants of Con A-stimulated peripheral blood mononuclear cells by adsorption with anti-human interferon-gamma did not abrogate the effect on monocyte $\alpha_{1}$ PI expression.

Effect of crude lymphokine on $\alpha_{1} P I$ expression in PiZZ monocytes. Synthesis of $\alpha_{1}$ PI by PiZZ monocytes also increased in the presence of lymphokine (Fig. 7). Furthermore, the increase in the 52,000-mol wt intracellular form of $\alpha_{1} \mathrm{PI}$ in PiZZ monocytes treated with lymphokine is accentuated when compared with the change in the $55,000-\mathrm{mol}$ wt native extracellular $\alpha_{1} \mathrm{PI}$. The accentuation of intracellular $\alpha_{1} \mathrm{PI}$ accumulation in PiZZ monocytes by the lymphokine was selective, in that total TCAprecipitable protein and other specific proteins were not similarly affected. Factor B and C3 (Fig. 7, center and right) were increased proportionally in intracellular lysates and extracellular media of lymphokine-treated PiZZ monocytes.

\section{Discussion}

The results of these experiments demonstrate that a product of mitogen-stimulated peripheral blood mononuclear cells increases 

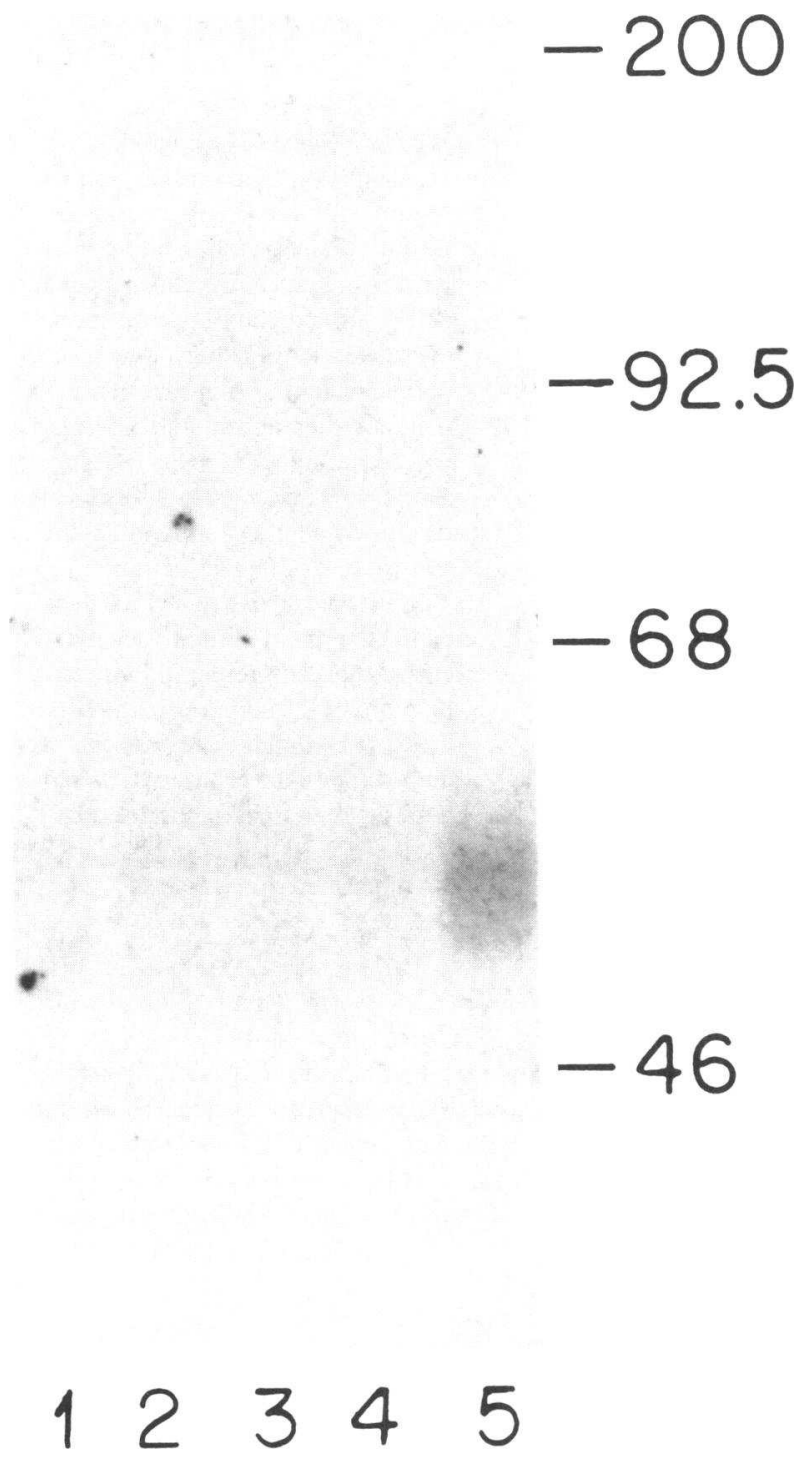

Figure 6. Controls for the effect of lymphokine supernatants on synthesis and secretion of $\alpha_{1}$ PI by monocytes. Extracellular medium from radiolabeled monocytes after $9 \mathrm{~d}$ in culture were immunoprecipitated with anti-human $\alpha_{1}$ PI. Before labeling, monocytes were incubated for $48 \mathrm{~h}$ with medium alone (lane 1 ), medium supplemented with Con $\mathrm{A}$ $2 \mu \mathrm{cg} / \mathrm{ml}$ (lane 2), medium supplemented with the supernatant of unstimulated mononuclear cells at 1:10 dilution (lane 3), medium supplemented with the supernatant of unstimulated mononuclear cells at 1:10 dilution and Con A $2 \mu \mathrm{cg} / \mathrm{ml}$ (lane 4), and medium supplemented with the supernatant of Con A-stimulated peripheral blood mononuclear cells at 1:10 dilution (lane 5). Molecular mass markers are indicated.

the expression of $\alpha_{1} \mathrm{PI}$ in human monocytes and macrophages by a pretranslational mechanism. This factor also increases the expression of $\alpha_{1}$ PI by monocytes from homozygous PiZZ-deficient individuals, and in so doing, accentuates the defect in secretion of $\alpha_{1} \mathrm{PI}$ in these individuals. The regulating factor has the characteristics of a polypeptide and is probably elaborated by T lymphocytes, but it is not an interferon or IL-2.

The expression of $\alpha_{1}$ PI by monocytes is also regulated by time in culture and by interaction with serine protease (7). During the first $24 \mathrm{~h}$ in culture, synthesis and secretion of $\alpha_{1} \mathrm{PI}$ is maximal and $\alpha_{1} \mathrm{PI}$ appears in the cell culture fluid in native and proteasecomplexed forms. Synthesis and secretion of $\alpha_{1}$ PI progressively decreases during the first week in culture, but the small amount of $\alpha_{1}$ PI detectable in cell culture fluid by 7-10 dis almost entirely in native form. These data suggest that the serine protease(s) which interacts with $\alpha_{1}$ PI early in culture is either passively adsorbed to the cell surface but progressively lost during culture or that de novo synthesis of serine protease(s) by monocytes decreases abruptly during the first $4 \mathrm{~d}$ in culture. In either case, the factor present in supernatants of mitogen-stimulated peripheral blood mononuclear cells independently regulates the expression of $\alpha_{1} \mathrm{PI}$, since only the native 55,000 -mol wt form increased in cell culture fluid of treated monocytes. It might be argued that serine protease expression was also increased by this lymphokine but not detected because a corresponding increase in release of oxygen radicals resulted in functional inactivation of $\alpha_{1} \mathrm{PI}$. This possibility was excluded by demonstrating the formation of a complex after the addition of exogenous protease to the cell culture fluid of lymphokine-treated monocytes.

Changes in the expression of $\alpha_{1} \mathrm{PI}$ in monocytes during culture are not simply a reflection of cellular differentiation. Although $\alpha_{1} \mathrm{PI}$ is secreted in native form alone by the "late" monocyte and alveolar macrophage, it is also in complex form in the cell culture fluid of breast milk macrophages. Expression of $\alpha_{1} \mathrm{PI}$ in macrophages of either type decreases over 7-10 $\mathrm{d}$ in culture while synthesis of total TCA-precipitable protein and other specific proteins remains unchanged. Finally, the ratio of $\alpha_{1} P I$ in native to complexed form and the apparent size of complex forms vary between monocyte and breast milk macrophage, suggesting that there is independent regulation of serine protease and $\alpha_{1} \mathrm{PI}$ in different local microenvironments. The expression of several other mononuclear phagocyte secretory proteins is increased by lymphokines. Interferon-gamma mediates an increase in expression of complement proteins $\mathrm{C} 2$ and factor $\mathrm{B}$ in monocytes and macrophages (24). Crude lymphokine supernatants increase synthesis and secretion of $\mathrm{Cl}$ inhibitor (25), plasminogen activator urokinase (26), and procoagulant activity (27) by monocytes. The lymphokine responsible for enhanced monocyte procoagulant activity is also derived from a $\mathrm{T}$ lymphocyte of the helper/inducer subset (28). A separate T lymphocyte cell-associated pathway may also increase monocyte procoagulant activity (28-30). Further studies will be necessary to identify the source and identity of the mediator(s) responsible for the increase in expression of $\alpha_{1}$ PI by monocytes and macrophages.

Most important, however, will be further studies of regulation of mononuclear phagocyte $\alpha_{1} \mathrm{PI}$ expression by lymphokine as a model for the effect of enhanced synthesis on a defect in posttranslational processing/secretion, i.e., homozygous PiZZ $\alpha_{1} \mathrm{PI}$ deficiency. If the presence or severity of intracellular $\alpha_{1} \mathrm{PI}$ accumulation is a factor involved in the development of chronic liver disease and/or pulmonary emphysema, differences in the elaboration of this lymphokine and similar mediators in the local environment of the target organs may contribute to the wide variability in disease manifestations among PiZZ individuals.

\section{Acknowledgments}

We thank Claudia S. Leonard and Pat Punsal for technical assistance, Harvey R. Colten for advice, and Helen Hourihan for secretarial assistance. 

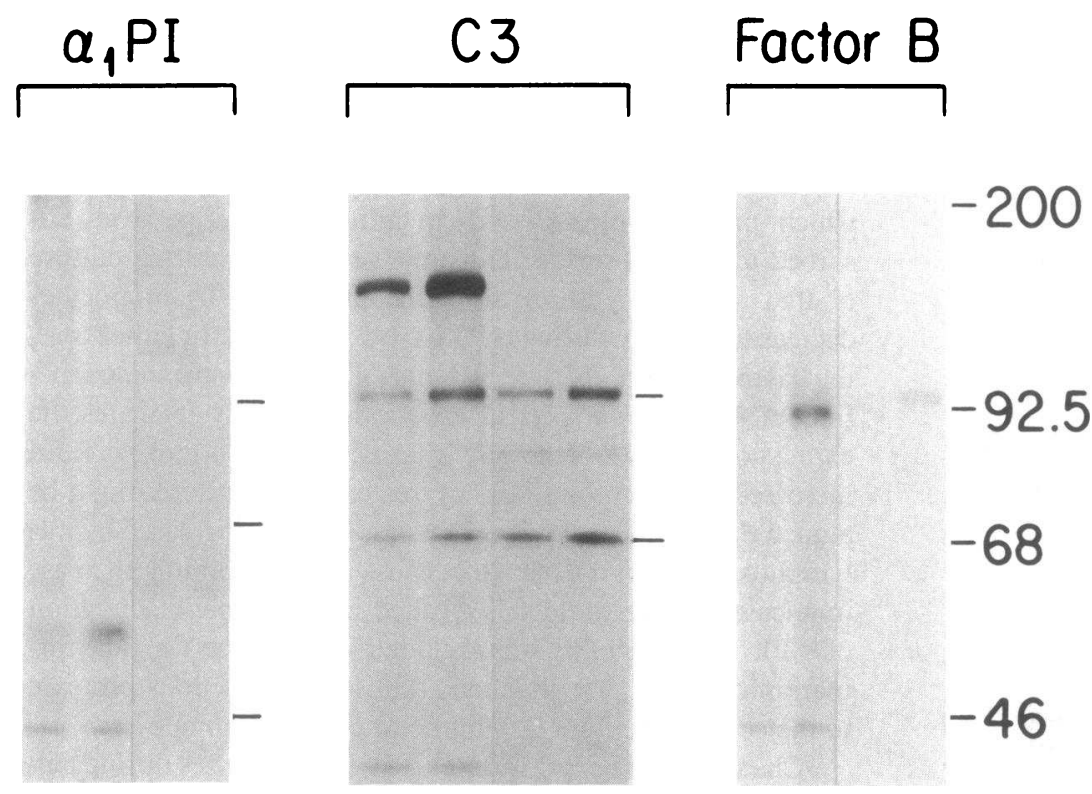

Figure 7. Effect of lymphokine supernatants on synthesis and secretion of $\alpha_{1} \mathrm{PI}$ and $\mathrm{C} 3$ by monocytes from PiZZ individuals. Intracellular lysates (IC) and extracellular media (EC) from radiolabeled PiZZ monocytes after $9 \mathrm{~d}$ in culture were immunoprecipitated with antihuman $\alpha_{1}$ PI (left) and then anti-human $\mathrm{C} 3$ (center) or anti-human Factor B (right). Monocytes were incubated with control supernatant $(-)$ or lymphokine supernatant $(+)$ at $1: 10$ dilution for $48 \mathrm{~h}$ before labeling. Total TCA-precipitable protein did not vary significantly between samples. Fluorography for lanes containing extracellular media (EC) in left panel was con-
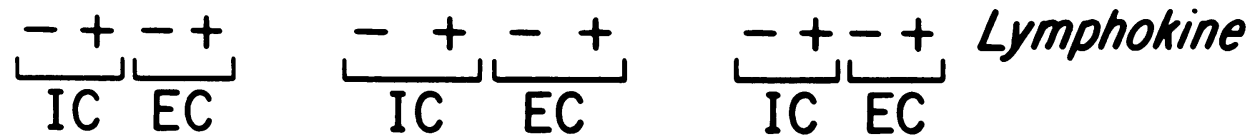
ducted for $18 \mathrm{~d}$ as compared with 7 d for lanes containing intracellular lysates (IC). Molecular mass markers are indicated.

These studies were supported in part by Charles H. Hood Foundation, American Gastroenterological Association/Industry Research Scholar Award, and by the U. S. Public Health Service (AM07114 and AI20959).

\section{References}

1. Gadek, J. E., and R. G. Crystal. 1983. Alpha ${ }_{1}$ antitrypsin deficiency. In Metabolic Basis of Inherited Disease. J. B. Stanbury, J. B. Wyngaarden, D. S. Fredrickson, J. Goldstein, and M. S. Brown, editors. McGraw-Hill Book Co., New York. 1450-1467.

2. Long, G. L., T. Chandra, S. L. C. Woo, E. W. Dane, and K. Kurachi. 1984. Complete sequence of the cDNA for human alpha $a_{1}$ antitrypsin and the gene for the $S$ variant. Biochemistry. 23:4828-4837.

3. Pearson, S. J., P. Teton, D. L. George, and U. Francke. 1983. Activation of human alpha $a_{1}$ antitrypsin gene in rat hepatoma $x$ fetal liver cell hybrids depends on the presence of chromosome 14. Somat. Cell Genet. 9:567-592.

4. Lai, E. C., F. Kao, M. L. Law, and S. L. C. Woo. 1984. Assignment of the alpha $a_{1}$ antitrypsin gene and a sequence-related gene to human chromosome 14 by molecular hybridization. Am. J. Hum. Genet. 35: 385-392.

5. Hood, J. M., L. J. Koep, R. L. Peters, G. P. J. Schroter, R. Weil, A. G. Redeker, and T. E. Starzl. 1980. Liver transplantation for advanced liver disease with alpha ${ }_{1}$ antitrypsin deficiency. N. Engl. J. Med. 302: 272-275.

6. Alper, C. A., D. Raum, Z. L. Awdeh, B. H. Petersen, P. D. Taylor, and T. E. Starzl. 1980. Studies of hepatic synthesis in vivo of plasma proteins including orosomucoid, transferrin, alpha ${ }_{1}$ antitrypsin, C8 and factor B. Clin. Immunol. Immunopathol. 16:84-89.

7. Perlmutter, D. H., F. S. Cole, P. Kilbridge, T. H. Rossing, and H. R. Colten. 1985. Expression of the $\alpha_{1}$ proteinase inhibitor gene in human monocytes and macrophages. Proc. Natl. Acad. Sci. USA. 82: 795-799.

8. Perlmutter, D. H., R. M. Kay, F. S. Cole, T. H. Rossing, D. H. Van Thiel, and H. R. Colten. 1985. The cellular defect in homozygous PiZZ $\alpha_{1}$ PI deficiency is expressed in xenopus oocytes injected with human liver RNA and in human monocytes. Proc. Natl. Acad. Sci. USA. 82: 6918-6921.
9. Carrell, R. W., and M. C. Owen. 1979. Alpha antitrypsin: structure, variation and disease. Essays Med. Biochem. 4:83-119.

10. Sztein, M. B., P. S. Steeg, H. M. Johnson, and J. J. Oppenheim. 1984. Regulation of human peripheral blood monocyte DR antigen expression in vitro by lymphokines and recombinant interferons. J. Clin. Invest. 73:556-565.

11. Einstein, L. P., E. E. Schneeberger, and H. R. Colten. 1976. Synthesis of the second component of complement by long-term primary cultures of human monocytes. J. Exp. Med. 143:114-126.

12. Cole, F. S., W. J. Matthews, T. H. Rossing, D. J. Gash, N. A. Lichtenberg, and J. E. Pennington. 1983. Complement biosynthesis by human bronchoalveolar macrophages. Clin. Immunol. Immunopathol. 27:153-159.

13. Cole, F. S., E. E. Schneeberger, N. A. Lichtenberg, and H. R. Colten. 1982. Complement biosynthesis in human breast milk macrophages and blood monocytes. Immunology. 46:429-441.

14. Boyum, A. 1968. Isolation of mononuclear cells and granulocytes from human blood. Scan. J. Clin. Invest. 21:77-86.

15. Umetsu, D. T., D. Y. M. Leung, R. Siraginian, H. H. Jabara, and R. S. Geha. 1985. Differential requirements of $B$ cells from normal and allergic subjects for the induction of IgE synthesis by an alloreactive T cell clone. J. Exp. Med. 162:202-214.

16. Roberts, B. E., and B. M. Paterson. 1973. Effect of translation of tobacco mosaic virus RNA and rabbit globin 6S RNA in a cell-free system from commercial wheat germ. Proc. Natl. Acad. Sci. USA. 70: 2330-2334.

17. Laemmli, U. K. 1970. Cleavage of structural proteins during the assembly of the head of bacteriophage T4. Nature (Lond.). 227:690-695.

18. Chirgwin, T. M., A. E. Przybyla, R. J. MacDonald, and W. J. Rutter. 1979. Isolation of biologically active ribonucleic acid from sources enriched in ribonuclease. Biochemistry. 18:5294-5301.

19. Thomas, P. 1980. Hybridization of denatured RNA and small DNA fragments transferred to nitrocellulose. Proc. Natl. Acad. Sci. USA. 77:5201-5205.

20. Rogers, J., N. Kalsheker, S. Wallis, A. Speer, C. H. Coutelle, D. E. Woods, and S. E. Humphries. 1983. The isolation of a clone for human alpha $a_{1}$ antitrypsin and detection of alpha $a_{1}$ antitrypsin mRNA from liver and leucocytes. Biochem. Biophys. Res. Commun. 116:375-382. 
21. Woods, D. E., A. Markham, A. Ricker, G. Goldberger, and H. R. Colten. 1982. Isolation of cDNA clones for the human complement protein factor B, a class III major histocompatibility complex gene product. Proc. Natl. Acad. Sci. USA. 80:4464-4468.

22. Strunk, R. C., A. S. Whitehead, and F. S. Cole. 1985. Pretranslational regulation of the synthesis of the third component of complement in human mononuclear phagocytes by the lipid A portion of lipopolysaccharide. J. Clin. Invest. 76:985-990.

23. Boldt, D. H., S. K. Chan, and K. Keaton. 1982. Cell surface $\alpha_{1}$ protease inhibitor on human peripheral blood mononuclear cells in culture. J. Immunol. 129:1830-1836.

24. Strunk, R. C., F. S. Cole, D. H. Perlmutter, and H. R. Colten. 1985. Gamma-interferon increases expression of MHC class III complement genes $\mathrm{C} 2$ and factor $\mathrm{B}$ in human monocytes and in murine fibroblasts transfected with human $\mathrm{C} 2$ and factor B genes. J. Biol. Chem. 260:15280-15285.

25. Bensa, J. C., A. Reboul, and M. G. Colomb. 1983. Biosynthesis in vitro of complement subcomponents $\mathrm{Clq}, \mathrm{Cls}$ and $\mathrm{Cl}$ inhibitor by resting and stimulated human monocytes. Biochem. J. 216:385-392.
26. Vassalli, J. D., and E. Reich. 1977. Macrophage plasminogen activator: induction by products of activated lymphoid cells. J. Exp. Med. 145:429-441.

27. Helin, H., and T. S. Edgington. 1984. A distinct "slow" cellular pathway involving soluble mediators for the $\mathrm{T}$ cell-instructed induction of monocyte tissue factor activity in an allogeneic immune response. $J$. Immunol. 132:2457-2463.

28. Gregory, S. A., and T. S. Edgington. 1985. Tissue factor induction in human monocytes: two distinct mechanisms displayed by different alloantigen responsive T cell clones. J. Clin. Invest. 76:2440-2445.

29. Levy, G. A., and T. S. Edgington. 1980. Lymphocyte cooperation is required for amplification of macrophage procoagulant activity. $J$. Exp. Med. 151:1232-1244.

30. Helin, H. J., R. J. Fox, and T. S. Edgington. 1983. The instructor cell for the human monocyte procoagulant response to bacterial lipopolysaccharide is a Leu $3 \mathrm{a}+\mathrm{T}$ cell by fluorescence-activated cell sorting. J. Immunol. 131:749-752. 